\title{
Nurses Burnout, Resilience and Its Association with Safety Culture: A Cross Sectional Study
}

\author{
Mohammed Majrabi \\ Eradah Hospital for Mental Health, Jazan, Saudi Arabia \\ Email: mmajrabi@outlook.sa
}

How to cite this paper: Majrabi, M. (2022) Nurses Burnout, Resilience and Its Association with Safety Culture: A Cross Sectional Study. Open Journal of Nursing, 12, 70-102. https://doi.org/10.4236/ojn.2022.121006

Received: June 9, 2021

Accepted: January 26, 2022

Published: January 29, 2022

Copyright (c) 2022 by author(s) and Scientific Research Publishing Inc. This work is licensed under the Creative Commons Attribution International License (CC BY 4.0).

http://creativecommons.org/licenses/by/4.0/

\begin{abstract}
Background: The focus of this study was on burnout, resilience and its effect on safety culture. The study maintained that healthcare organizations lag behind in the race to address burnout because they focus more on dealing with the already-existing burnout other than focusing on the source. Aims: To assess burnout, resilience and its association to safety culture in nurses working in mental health institutions with psychiatric patients in Jazan, Saudi Arabia. Method: The study design was a cross sectional survey using convenience sampling, and 119 participants from Al-Amal and psychiatric hospital in Jazan in the period between June and August 2018. A self-administered questionnaire was used to assess burnout, resilience and its association to safety culture. Results: A large percentage of nurses feel that the appropriate information about performance is not presented to them. They feel that they are deprived of a great working day and environment and plan to leave their current workplaces to get better opportunities where their career opportunities are more appreciated. Findings: A significant percentage of nurses feel that appropriate feedback about performance is not offered to them. They feel their careers are unappreciated and are burned out on a typical workday and plan to leave their current workplaces for better opportunities. Conclusion: This study supported the adoption of healthcare mechanisms to address the source of nurse's burnout than addressing this issue when it emerges. The focus on the source can prove effective in building resilience and supporting safety culture.
\end{abstract}

\section{Keywords}

Nurses' Burnout, Resilience, Safety Culture 


\section{Introduction, Overview, Background, and Research Context}

\subsection{Introduction}

This chapter provides background information concerning the study and an overview of the research context and concludes with an overview of the thesis structure.

\subsection{Overview of Nurse's Burnout, Resilience and Safety Culture}

The healthcare sector plays a fundamental role in societal wellness. In healthcare, nurses as well as doctors contribute to a culture of safety in their organizations and institutions. A safety culture aims to maintain the duty of care for patients. [1] explained that patient safety and a safety culture is the foundation of healthcare. In a healthcare setting where a patient feels unsafe, healthcare providers find themselves in a complex situation to achieve their duties [1]. A safety culture promotes proper healthcare delivery and minimizes the occurrence of errors of omission, commission, communication, context, and diagnosis [1]. Avoiding all these errors is possible only if healthcare institutions address the issues that support their occurrence. Committing to patient safety and focusing on improving a safety culture lies in the hands of healthcare providers and their institutions. However, the two, healthcare institutions and health providers should each play their role diligently for a safety culture to prevail.

Although patients desire a safe environment supported by a safety culture, healthcare providers often find themselves intertwined between their commitment to quality and safe care and the complex, high-pressure nature of the healthcare environment. While doctors and other healthcare providers contribute immensely in meeting patient needs, nurses are tasked with the greatest responsibility. In healthcare delivery, nurses constitute the largest component of the workforce [2]. The role of nurses in providing quality care in a safety culture requires them to attend to patients twenty-four hours and seven days a week, nurse provided care daily [2]. Among other roles, nurses examine patient clinical changes, activate care provider activities, coordinate, and integrate care services [2]. Such high demands, however, remain invisible until nurses are exposed to clinical errors that compromise a safety culture.

The extensive role of nurses in care provision subjects them to heavier workloads and sometimes-long shifts. Working for long hours and attending to many patients with extensive care needs strains nurses, exposing them to burnout and reduced resilience. Various research studies focused on the role of nurses in healthcare and the contributing factors to their ineffectiveness outlined the relationship between nurses' workload and burnout. In one of the studies, [3] explained that the relationship between nurse workload and burnout is evident. According to the authors, the extensive workload leads to exhaustion, which is a basic component of burnout. Many healthcare organizations experience nurse burnout due to low decision latitude that promotes high psychological demands respon- 
sible for the resultant burnout [3]. When nurses experience and exhibit burnout the possibility for them to exhibit dysfunctional psychological responses to their duties erupts. Psychological morbidity, which results from burnout, hinders resilience and can lead to anxiety or other symptoms that diminish a safety culture in healthcare delivery [4]. Nurse burnout and limited resilience support negative implications on healthcare's safety culture.

\subsection{Background}

\subsubsection{Burnout}

Burnout entails the psychological syndrome that develops when individuals suffer from stressful job demands and fewer resources for use [5]. Burnout affects individuals in all aspects, including physical, mental and emotional aspects to leave the individuals underproductive and underperforming [5]. In healthcare, nurses are more prone to burnout than doctors and other care providers. Burnout in healthcare arises from the stressful work conditions and unmet job expectations. [5] agree that medical practice is stressful since healthcare professionals need to constantly respond to patient needs and demands. In healthcare, a safety culture is free from medical errors. However, irreversible and costly errors sometimes occur and are largely attributed to burnout. Basically, burnout is characterized by emotional exhaustion, reduced personal accomplishment and depersonalization [5]. As individuals experience burnout, their susceptibility to mistakes arises.

For a long time, occupational burnout in nursing has formed the core of nursing studies looking into the effectiveness of nurses in their roles and responsibilities. By default, nurses are subject to occupational stress since they perform in stressful situations, healthcare organizations and patients expect them to perform highly and they find the patient-nurse relationships complicated [6]. [6] believe that nurse burnout results from the nurse inability to handle emotional exhaustion and the depersonalization that trail their roles and responsibilities. Instances of burnout, combined with the high nurse-to-patient ratio and the rapid growth of the aging population in care institutions requiring critical care, explain the diminishing of the safety culture. Psychological distress is a negative contributor to poor nurse outcomes. In instances of psychological distress, the quality of life is affected [6].

\subsubsection{Resilience}

The high burnout does not represent the quality of all nurses. Nurse-limited resilience depend on several factors, including the ability of a nurse to adapt to their work environment and their needs [6]. Nurse burnout breeds limited resilience, which is defined as the individual capacity, the process that their work subjects them to and the result of their capacity, and work processes [6]. The level of resilience depends on burnout, with high burnout levels greatly influencing resiliency negatively. A safety healthcare culture should strive to support resilience by limiting factors that promote nurse fatigue [7]. Healthcare leaders, 
however, often fail to cancel out burnout and its growth influences nurse and other care providers' resilience. Although resilience is the degree of the impact of the relationship between individual capacity and work process, it can also be defined in terms of the degree of adjustment of individuals to work pressure [7]. The ability to cope successfully without the influence of the negative factors surrounding working environment defines resilience [7].

In the absence of burnout, resilient individuals exhibit positive relations and emotions, including secure attachments, effective engagement, personal goals and self-efficacy among other attributes [7]. However, for nurses, burnout diminishes resilience greatly.

\subsubsection{Safety Culture}

Many factors contribute to burnout, apart from long working hours and patient care demands. In healthcare, a healthcare organization's culture and workplace bullying contribute to turnover intention [8]. [8] reported that workplace turnover intention is largely attributed to burnout more than other factors such as compensation. With the increased healthcare provider job demands that exceed personal capacity, these providers feel drained and relish opportunities to shift from their current workplace. When health providers divide their attention between serving in their current organization and seeking better work opportunities that offer safe working environments, they find themselves experiencing a decline in their efficiency and suffer from negative socioeconomic experiences that hinder their productivity [8]. On the other hand, an organization's culture greatly influences nurse care provision and commitment to impact a culture of safety. An organization's culture entails beliefs, values and behavioral patterns, which if not properly monitored, can drain healthcare providers especially nurses [8]. In the case of nurses, their experiences pertaining to workplace culture determines their nature and rate of input in their responsibilities and a negative or less engaging culture can easily subject them to burnout and limited resilience.

\subsection{Brief Review of Current Knowledge}

\subsubsection{Nurse Burnout}

Many researchers have studied burnout in healthcare with the research studies giving similar findings. In one study, [9] the authors studied nurse burnout in nurses working in a military hospital. Before the study, the authors believed that burnout is an occupational stress that contributes to loss of efficacy and absenteeism from work [9]. Due to high stress levels in professional environments, burnout erupts to leave workers underperforming [9]. In the study, the authors held the belief that burnout is the exhaustion that cultivates the thoughts to leave one's workplace for better opportunities [9]. Burnout, which leads to emotional exhaustion, makes nurses hopeless, depressed and helpless, and the situation negatively influences their care delivery. Eroding a nurse's sense of effectiveness is a negative factor that makes burnout a point of concern for healthcare leaders. 


\subsubsection{Nurse Resilience Effects (Positive and Negative)}

In high-intensity care settings, nurses are most exposed to workplace burnout more than in low-intensity settings. In a study to understand nurse resilience in high-intensity care settings, [10] explained that high stress levels in nurses, which results into reduced resiliency, expose them to negative behavioral effects such as depression and anxiety. However, it is no surprise that nurses are often exposed to burnout since their job requirements demand them to work in high-stress levels throughout their careers [10]. In care settings, nurses deal with a lot of disturbing patient issues, including dying patients, patient spiritual demands and the uncertainty surrounding their work conditions [10]. The authors further add that burnout does not directly contribute to resilience which in turn influences a safety culture. Instead, when nurses realize their moral problem, which arises from the lack of moral ability to act according to their job demands without draining them, the job demands drive them out of position and subject them to reduced resilience.

\subsubsection{Safety Culture}

In life, work is a basic component that takes a great proportion of an individual's life. Work implicates life positively and negatively depending on the angle of view. Whereas positive work stimuli influence life positively, negative work stimuli influence life negatively. The work structure of nurses makes them one of the most susceptible population to work burnout [11]. Critical decision-making and the need to care for critical patients automatically complicates nurses' work environment and subjects them to stressful conditions that limit their resilience. Despite the role of the nursing work environment in nurse burnout and resilience, nurses still should offer quality care despite the existence or non-existence of a safety culture [12].

\subsection{Summary of the Chapter}

The proliferation of burnout among nurses is posing an increasing risk to health care in Saudi Arabia. There is an increasing rise in the turnover and intention to leave the work place with only limited information on the potential harm caused by workload and lead to burnout, there will be an increase in the demand for data to describe the specific nature of these trends towards improving targeted prevention strategies with effective intervention.

\subsection{The Structure of the Thesis}

This thesis presents a study to assess burnout, resilience and association to safety culture among nurses working at Alamal and Psychiatric Hospital, Jazan. The first chapter outlines the background to the study and the structure of the thesis. Chapter two's review of literature identifies and discusses studies of nurses' burnout, resilience and safety. It concludes by identifying gaps in previous research and presents the rationale for the study, study aims and research questions of the study. Chapter three provides a description of the contextual settings 
in which this study took place. It describes the methodology and methods of the study and the rationale for adopting a research design. A detailed explanation is then given for the methods, along with the ethical considerations that shaped the research. The study procedure is described, including participant recruitment and methods of data collection and analysis. Chapter four presents the findings of the study, including a description of the study sample and the socio-demographic characteristics. In addition, it discusses the results of analysis performed on each domain scale. Chapter five (discussion chapter) summarizes the findings and discusses them in the context of the existing literature and the study recommendations.

\section{Literature Review}

\subsection{Introduction}

This chapter provides a detailed review of existing literature and published studies related to nurse burnout, resilience and its association to safety. It also details the process of conducting the review, its search strategy, and inclusion and exclusion criteria. The chapter concludes with the identification of gaps in previous studies and the current study justification.

\subsection{Aims}

The main aim of this comprehensive literature review was to examine and update the synthesised evidence regarding the assess nurse's burnout, resilience and its associations to safety culture. It also aimed to identify gaps in the literature.

\subsection{Objectives}

The objectives of the review were to:

- Identify studies investigated the nurse's burnout, resilience and its association to safety.

- Determine the most common outcome measure used to assess these variables.

\subsection{Literature Search Strategy}

The literature review addressed studies that assess nurse's burnout, resilience and its association to safety. For the purposes of this review, the population was defined as nurses whom working at Psychiatric hospital. The search was restricted to studies published in English during the period of 2012 to 2019. Applying the Population, Interventions, Comparators, Outcomes, and Designs (PICOT) format (CRD, 2009), the search employed the following key and associated terms:

Population-nurses (who work at hospital)

Interventions (interest)-NOT APPLICABLE.

Context Outcomes of interest-nurses burnout, resilience and its association to safety. 
Designs-studies that conducted in any of the following designs were included:

- Randomised controlled studies: random assignment participant either to the intervention group or to the control group with follow-up (any format of RCT).

- Quasi-experimental studies

- Qualitative studies

- Mixed Method studies: including two different methods of data collection (i.e. questionnaires or interviews, focus group).

\subsection{Data Sources and Screening Procedure}

A comprehensive literature search was conducted to determine the relevant studies using the following electronic databases via Saudi digital library (SDL): MEDLINE, PubMed, CINAHL and Google Scholar from 2012 to 2019. Searches were limited to nurses working in clinical setting. The current study includes papers written either in English during the period of 2012 to 2019. The reason for choosing this time interval was to obtain up-to-date knowledge of this area of research to inform practice. In addition, there were only a limited number of studies published before 2012 .

The general keywords used in the search were nurses burnout/ resilience and/ safety culture. The studies' titles and abstracts were initially screened against inclusion criteria to determine potentially relevant studies. In the case of ambiguity of content, the full texts of the articles were consulted to identify content relevancy for the current study. All duplicated studies from different databases. Reference lists of all included studies were compiled and examined to identify further relevant works.

\subsection{Results}

\subsubsection{Data Extraction}

The initial screening of the abstracts yielded 118 studies concerning the assess nurses burnout resilience and safety culture, of which 30 studies were excluded after reviewing their titles or being duplicated from different databases. Abstracts were then reviewed and 32 studies were also excluded because they did not meet the inclusion criteria, such as:

- Published outside the time period considered by this study (i.e., pre-2012) (n $=22$ ).

- Published in language other English $(\mathrm{n}=10)$

The full text of 118 articles was reviewed comprehensively to identify gaps in the literature, after which 62 articles were excluded for several reasons. Thus, 56 studies were ultimately included in the review, having met the inclusion criteria to learn more about the nature of these studies.

\subsubsection{Current Literature on Nurse Burnout}

In healthcare, and especially for nurses (Figure 1), burnout is a common problem 


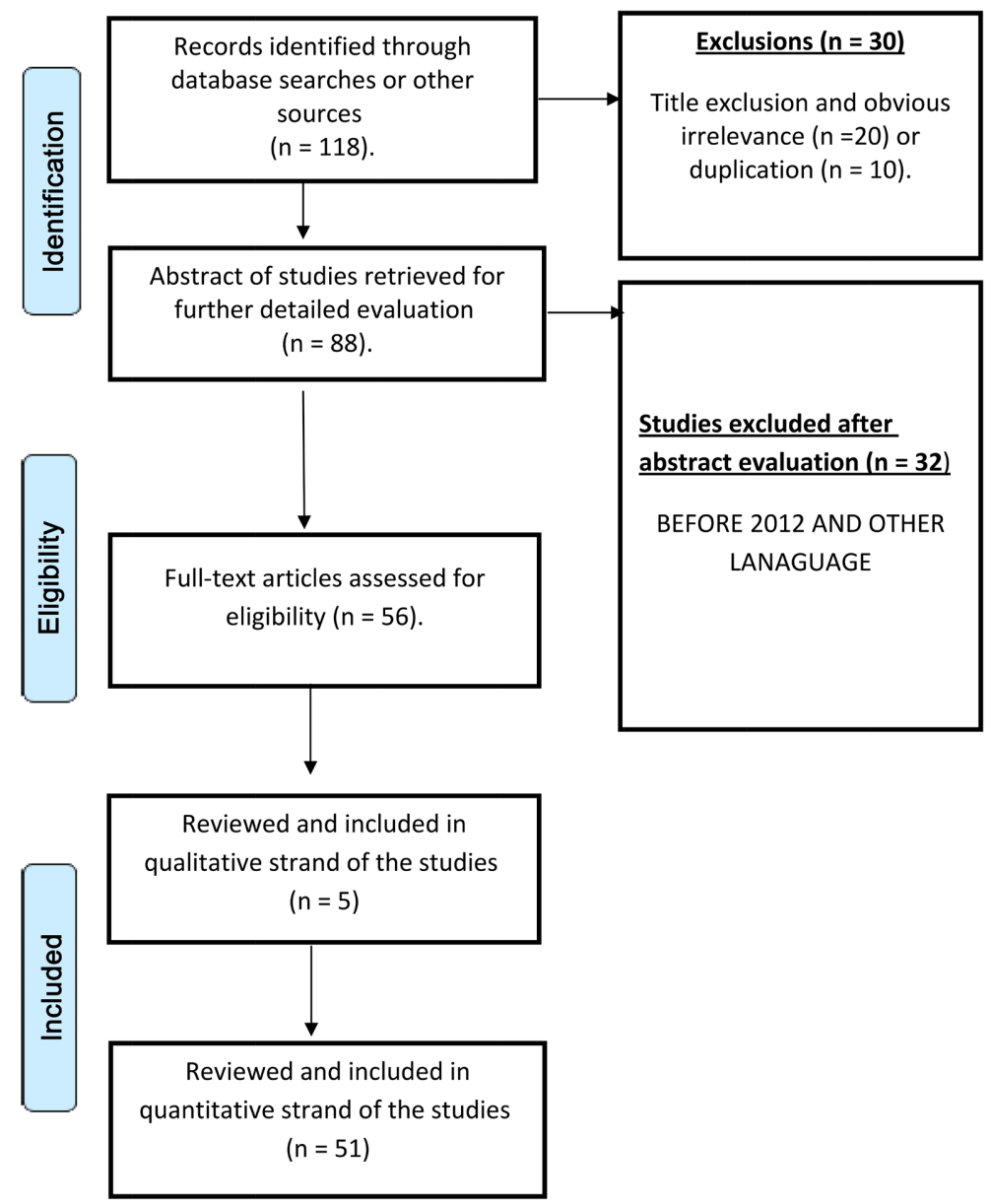

Figure 1. Flow diagram of the data retrieved at each stage of the review.

that healthcare leadership and management can fail to notice. Nurses that experience burnout suffer from its effects on and off duty [13]. In a study to establish the level of burnout in Intensive Care Units (ICUs) in Zimbabwe, [13] remarked that it is often uncommon for nurses in these units not to experience burnout. Nurses in ICUs experience burnout since they worry more about attending to their patients than about their personal emotions [13]. The nurses experience burnout because of the critical condition of patients in this type of care. Studying 23 nurses working in ICUs in Zimbabwe, the study revealed that about $78 \%$ of the studied nurses experienced burnout [13]. From the study results, the study revealed that for this population, the importance of identifying the factors contributing to burnout early can prove effective in handling this healthcare vice affecting nurses [13]. This study did not establish the real causes of burnout or the methods to address their occurrence than dealing with them when they arise, leaving a knowledge gap for exploration.

Burnout is a psychological syndrome emerging as a prolonged response to chronic interpersonal stressors on the job. The three key dimensions of this response are an overwhelming exhaustion, feelings of cynicism and detachment from the job, and a sense of ineffectiveness and lack of accomplishment. 
[14] defined burnout as physical, emotional and mental exhaustion state caused by long-term involvement in situations that are emotionally demanding. Since burnout was first described in the early 1970s, thousands of conceptual papers and empirical studies have focused on this complex phenomenon. As research burgeoned over the past three decades, it has become clear that burnout, which occurs cross culturally, is prevalent across a variety of occupations, including teachers, managers and clerical workers, and in a variety of fields, including education, business, criminal justice, and computer technology [15].

[16] offered new perspectives into burnout. The authors believed that burnout is a long-term impact that leads to the loss of interest in one's work [16]. Due to the loss of interest, workers experiencing burnout suffer health effects that influence their psychological status. Burnout is often associated with feelings of dissatisfaction and difficult working conditions. In this particular study, [16] studied the predictors of burnout in Egyptian nurses. The results indicated that the studied nurses reported work burden, years of experience, supervision and work-related violence among the actors that predicted nurse burnout [16]. According to these findings, it is easier to predict burnout provided healthcare leaders and managers focus more on working on the predictors by handling their possible sources. The identified predictors, work burden, years of experience, supervision and work-related violence, should form the core of burnout research in healthcare institutions focused on nurses. Healthcare leaders and managers should strive to assist individuals that fall under these categories not to develop any signs of burnout. The gap left in this research provides a serious issue of concern needing research attention.Sources of job stress that have been cited to contribute to burnout among nurses include organizational climate and structure, the job itself, achievement and family obligations, interpersonal relationships, and managerial roles such as being temporarily in-charge of the units. Managers are required to be attentive to these factors and introduce strategies that can help to minimize job-related stress and improve overall work outcome [9].

[9] conducted a study that determined burnout among military hospital nursing staff in Saudi Arabia and the risk factors associated with it. Their study revealed that the overall prevalence of burnout in the target group was high (75.9\%). The study also showed that inpatient nurses were presented with a greater risk of having burnout in comparison to those working in outpatient clinics. These findings further highlight the need to put in place burnout prevention interventions in this setting.

[17] conducted a study on burnout in Anaesthesia and Intensive Care. The researchers remarked that emotional exhaustion and loss of sense of achievement duly influence the focus of nurses to attend to their roles and responsibilities successfully. The researchers further added that in healthcare today, burnout cases tend to increase by the day and this rise may be due to increased awareness of burnout and diagnostic capabilities [17]. In line with the rise in burnout cases, 
a multidisciplinary approach and psychosocial model can help address the rising cases of burnout. Dealing with burnout is possible if healthcare providers focus on engaging the individual care providers and the healthcare community at large and educating healthcare providers early enough on burnout [17]. However, these strategies to deal with burnout are flanked by limited evidence, meaning that the methods to address the sources of burnout are still unclear to limited knowledge.

Nurses who tend to work in areas that are said to be high stress such as in critical care, pediatric units and oncology receive the highest levels of burnouts according to various reports. In most cases, the burnout is usually composed of emotional exhaustion, reduced personal accomplishment as well as the depersonalization. Another critical factor is that burnout among nurses has various impacts. These impacts include; decreased patient satisfaction, increased turnover of nurses as well as the presence of adverse health outcomes. This change is mainly driven by managers' perceptions of improved efficiency from reducing the number of nurse shifts a day, thus causing fewer handovers between shifts, fewer interruptions to clinical care provision and increased productivity due to a reduction in the overlap between two shifts [18].

In the nursing domain, contributors to burnout include issues such as distress, emotional and spiritual demands that tend to create a certain perception of excessive working loads. According to [10] dealing with deaths and dying, lack of good preparation to address emotional and spiritual needs, insufficient staff support, and moral distress are some of the other factors that might make nurses be subjected to nursing burnouts.

About the relationship that exists between resilience and nursing burnouts, it is worth noting that it is the role of resilience to help people be in a position to withstand and mitigate moral distress and burnouts. When defining the term, resilience tends to be that state whereby one can cope with strategies that are meant to reduce distress. Besides that, resilience usually entails external activities such as the development of problem-solving methods or even engaging in activities such as exercises as well as putting the in believing in the sense of the meaning of life and self-efficiency. From that observation, it is clear to conclude that the presence of resilience is one of the methods that can be used to reduce burnouts among nurses.

To understand burnouts, a good observation can be drawn in a case study in Mainland China. In this region, the rate of nurse burnout was high across the nation. A sample of 1100 nurses from Hunan province was investigated, and it was found out that around 34 percent of the nurses had the burnout symptoms. The number obtained was similar to that percentage of the nurse's nationwide. Another study that was conducted in China that involved around 1104 nurses further revealed that yes indeed that there was burn out among nurses. This is because it was reported that over $35 \%$ of nurses reported the burnout cases during that study. 


\subsubsection{Current Literature on Resilience}

In a study by [19], the researchers studied nurses working in the Neonatal Intensive Care Unit (NICU). In the study, the authors maintained that high sustained levels of stress contribute to irritability, fatigue, and detachment [19]. The struggle between life and work qualifies as a positive factor contributing to reduced resilience in the workplace. In the healthcare setting, new rules and technologies crop up every day and it is paramount for nurses and other care practitioners to understand their importance and observe protocol [19]. [19] defined resilience as the combined abilities and characteristics to bounce back or cope despite serious issues with work and the resultant stress. In this regard, the researchers explored the relationship between burnout (the stress and fatigue associated with work) and resilience (the ability to cope and bounce back from the stress). However, in this particular research study, the link between the source of the stress and managing the source before the stress rises to burnout levels misses. Partially, this study revealed the relationship between burnout and poor safety healthcare cultures. The [19] research study determined the association between burnout and resilience but the demand to establish the factors that influence a resilience is still necessary for this study.

The popularity and frequency of nurse burnout in care institutions require prior learning and training in dealing with this issue effectively. [20] believes that the implementation of strategies to foster success in nurse students can prove effective in building their resilience to apply to their careers. In resilience training, nurse students are introduced to the current and possible factors that affect the future or nursing [20]. In the process, nurse students will be prepared to engage their resilience [20]. Recommendations from the 2016 U.S. Summit on Interaction of Healthcare Worker Health and Safety explored the possibility of the relationship between burnout and job dissatisfaction. One of the recommendations from the summit stated that the integration of healthcare worker and patient safety systems can promote job satisfaction, minimize worker burnout and support resilience [21]. However, the connection between nurse student resilience training and the integration of health worker and patient safety programs needs exploration to identify measures to keep out nurse burnout and promote resilience.

Mindfulness in healthcare for care providers can assist in improving nurse resilience. By definition, mindfulness is the focus on openness, acceptance, and patience while handling a situation [22]. In mindfulness, it is not allowed to judge a situation [22]. Healthcare providers should be encouraged to practice mindfulness in dealing with their issues, including building their resilience. However, according to this specific research study, the link between mindfulness and resilience for safety culture is missing, pointing at a wide research gap. Mindfulness for healthcare providers is essential since, in today's healthcare setting, patient adverse effects and the increased rate of healthcare-associated infections have contributed to the stressful nature of care delivery [23]. Apart from 
healthcare-associated infections and patient adverse effects, workplace crises require mindfulness to rebuild resilience.

According to [24] a culture of safety in healthcare quality delivery depends on various other components that include giving safety a first priority, being open to the constructive handling of medical errors, committing to safety at the managerial level (administration and decision stockholders), focusing on learning and focusing on improving systems and procedures to support safety culture than shifting blame to individuals [25]. The focus on learning and improving systems can handle the sources of burnout successfully, which in turn will support improve nurse resilience to enhance their care delivery. However, there is a need to identify extra measures to combine with system improvements and learning for effective outcomes.

\subsubsection{Safety Culture}

In healthcare, reducing hospital errors is a major factor for safety culture and quality care. However, quality care is impossible in the face of burnout, which influences the resilience of care providers. A safety culture in healthcare should focus on threats to safety and reflect on learning and performance to minimize hospital errors [26]. Healthcare leadership should constantly perform effectively through hospital walk-rounds to identify threats to safety culture and address these concerns as a way of developing a safety culture and preparing their care providers to avoid burnout instances that may limit their resilience through unsafe cultures [27]. The assessment of a safety culture proves effective in identifying and addressing burnout and a burnout climate [27]. Feedback from healthcare leadership and management walk-rounds give insight into the nature of burnout and the role of various factors, including the teamwork climate towards this vice [27]. In this regard, healthcare leadership and management can promote safety culture to limit the occurrence of possible burnout and reduced resilience.

Burnout in healthcare institutions affects both health providers and their organizations. Healthcare employees experiencing burnout suffer from physical issues such as headaches and insomnia, relationship difficulties with their organizations and patients and mental problems such as anxiety and depression [28]. Many research studies have identified the causes of burnout that include work structure, job demands and other factors that support exhaustion [28]. Coping mechanisms provide a safe and appropriate option to address burnout issues in healthcare providers [29]. However, [29] resent that occupational stress is unavoidable. As a result, healthcare providers and institutions should seek to keep stress on manageable levels than seeking to eliminate the causes of stress. Instead of focusing on fighting the causes of stress, manageable stress is easier to deal with if care workers and healthcare institutions focus on building resilience. Resilience defines the ability to overcome challenging obstacles and gain the strength to deliver quality output [30]. However, a culture change can prove effective in supporting resilience and keeping worker stress at manageable levels. 
In healthcare, worker well-being is paramount to safety culture and quality care delivery. Most healthcare researchers and scholars believe that healthcare well-being includes physical, social and emotional wellbeing [31]. The interaction between human behaviors and healthcare complex infrastructure determines worker well-being [31]. Worker emotional, social and physical well-being determines the relationship between the worker, patients, and influences worker attitudes towards the patients. Meeting patient needs is not easy in the absence of a safety culture since culture defines the values, beliefs, and attitudes towards quality care delivery [32]. The need for high management standards comes into the picture where burnout issues seek to destabilize a safety culture [32]. Additionally, teamwork, cooperation, and proper communication can handle burnout sources and occurrence effectively in the presence of ideal management standards [32].

\subsection{Gaps in the Included Studies}

Although the studies reviewed have found burnout has negative impact on nurses, decreases resilience and affects patient safety .However, there is heterogeneity in the used outcome measures. In addition, almost all of the included studies were utilised same instrument. Additionally, it was observed that, based on the included studies, there is a less of studies conducted at mental health field.

\section{Knowledge Gap}

The existing knowledge on nurse burnout, resilience, and safety culture, has, however, failed to establish the means to deal with the unpredictable, complex nature of the nurse work environment. Burnout Syndrome (BOS) has developed into a menace in many high-demand [33]. Burnout typically results from work demands. However, research studies have not clearly explained the solutions to addressing the stressful and complicated nature of the nursing environment to reduce burnout cases.

\subsection{The Significance of the Study}

This research aimed to fill an important gap in literature. This is particularly important for research in assessing burnout among mental health nurses, resilience and its association to safety culture. While the study will add to a small body of knowledge, it will also have the potential to provide policy makers with evidence as how best to reduce burnout among mental health nurses delivering mental health care in Saudi Arabia.

This study aims to assess burnout in nurses working in mental departments with psychiatric patients. Through the knowledge that is realized in this study, the significance of addressing burnout and the adoption of its recommendations is proposed.

Research on human resilience has been done to try built data about nurses coping mechanism and understand how certain individuals, even when faced 
with challenges and risk factors or stressors are able to bounce back without lasting psychological damage and continue with their lives. Resilience has become an appealing concept because of its roots in a model of positive psychology.

Although the patient safety issue has become a major academic and public concern in Healthcare industries, in Saudi Arabia very few studies have evaluated the extent to which patient safety is a strategic priority among tertiary care hospitals. Therefore, it is very important to assess nurses' attitude of safety culture.

The knowledge will also prove a step forward in addressing burnout in nurses in working in mental health institutions with psychiatric patients and offer a blueprint for designing an educational program for reducing nurse burnout levels. by focusing in high level of burnout and improving resilience. adjust education programme depend on data from current study. Maintain the nursing profession, avoid turnover, and remain an attractive nursing environment.

That adds to a small body of knowledge, and it can also have the potential to provide policy makers with evidence as how best to reduce burnout among nurses delivering psychiatric and mental health care. This study will provide a database for burnout, resilience and safety culture. This is study is also considered a step for researcher to detect burnout among nurses working with psychiatric patient for further research in doctorate degree for designing an educational programme for reducing nurses burnout. This research aimed to fill an important gap in the literature.

\subsection{The Aim of the Study}

Assess burnout in nurses working in mental health institutions with psychiatric patients in Jazan, Saudi Arabia. Assess nurse burnout and its association with resilience. Examine the relationship between burnout and patient safety culture. To assess the nursing perceptions of patient safety culture at the work unit and hospital levels. To determine the relationship between patient safety culture of nurses and selected demographic variables. The aim of this study is to identify the level of stress, the major cause of burnout, resilience and its association to safety culture in nurses working in mental health institutions with psychiatric patients in Jazan, Saudi Arabia.

\subsection{Research Question}

What is burnout among nurses working with psychiatric patients in mental health institutions, its relationship with resilience and its effect on safety culture?

\section{Methods}

\subsection{Introduction}

This chapter discusses the research design and the methods utilized in the research. This chapter also presents the setting, sample and population, the study 
instruments and their psychometric properties, date collection methods to address the research questions, ethical issues and data analysis used to examine the outcome among the patient diagnosed with mental health diseases.

Methodology is the study of how we know the world or gain knowledge of it through the research process. This research seeks to determine the nature of burnout in nurses working in mental health institutions with psychiatric patients, its association with resilience and its impact on patient culture safety. Moreover, this chapter describes the chosen research design and the rationale for this choice, thereby clearly explaining the sample, data collection methods, the setting of the study, ethical issues and data analysis

\subsection{Research Design}

The present study was employed a cross sectional design survey. This method of research was used to enquire from the participants about their behavior, attitude and opinion. The purpose of the study was to assess nurses' burnout, resilience and its effect on safety

A cross-sectional design was adopted for this study, as it demonstrates an effective plan to measure the prevalence of research problem and helps to determine the ways, through which the research aims, and objectives are fulfilled.

\subsection{Setting}

The researcher conducted the study in Al-Amal and Psychiatric hospital in Jazan, Saudi Arabia. The hospital was established in 1993. It serves mental and addicted patients in the Western region. Moreover, the Al-Amal and Psychiatric hospital provides treatment to addicted patients from Aseer region. Al-Amal and Psychiatric hospital is a governmental hospital, providing free services for Saudi citizen and non-Saudi. The hospital has around 150 beds (100 for male and 50 foe females patient) and 135 nurses (78 male and 57 females nurses at hospital). The reason behind choosing this setting is that the availability of staff with burnout and had idea to transfer from hospital due to workload and it was easy to access by the researcher.

\subsection{Sampling}

This study sample aimed to include all nurses working in Al-Amal and Psychiatric Hospital based on nursing administration records. Sample was convenience sampling of all nurses working at the hospital.

\subsubsection{Sample Size}

Essential element of research design that significantly affects the validity and clinical significance of the findings identified in research studies [34]. Sample include all nurses working in Alamal and Psychiatric hospital working in Alamal and Psychiatric Hospital based on nursing administration records. Sample was convenience sample of all nurses working at hospital. 


\subsubsection{Outcome Measure}

\section{Recruitment and Data Collection Procedure}

In this particular study, the respondents were provided with questionnaire which was divided into two sections.

First part: is demographic data. The respondents were required to fill their personal details including age, gender, marital status, nationality, level of education, monthly income, ward, position, years of experience, residence, types, and number of shifts and number of patients assigned. Intention to leave the current job/position was assessed by asking the following question: "Do you have any plan to leave the current job/hospital in the near future".

Second part: is questionnaire derived by of the questionnaire contained three scales: the Maslach Burnout Inventory (MBI), the Safety Attitudes Questionnaire (SAQ) and the Connor-Davidson Resilience Scale (CD-RISC) that required the participants to fill in data depending on the nature of their work and perceived burnout.

\subsection{Ethical Approval}

Ethical approval was obtained from the directorate of health affairs-Jazan. Research center (Ref No: 1825) and from the Institutional Review Board (IRB) at Fakeeh college for Medical Sciences (Ref No: 30/IRB/2018).

Approval of this particular study, which focused on nurses burnout, resilience and its association to safety culture at Alamal \& Psychiatric Hospital at Jazan region of Saudi Arabia, was gained from the psychiatric hospital operating under the Ministry of Health. Moreover, approval of this study was gained from Institutional Review Board. Prior to the commencement of the data collection methods, information regarding the study purpose was provided to the directors of each of the psychiatric units. Similar to the directors, the nurses were informed about the purpose and the procedures undertaken to complete this study.

\subsubsection{Informed Consent}

Informed consent is a vital principle to protect the rights of participants while conducting a study (Benoliel, 1988) [36]. It is accepted practice in studies of individuals with mental health problems that they can understand the nature of research and to make a decision to participate [35].

For this study, the initial step in ensuring informed consent was to display an information poster prominently in the selected clinical settings to advertise the study and its purposes. Furthermore, the master student approached participants and handed out information sheets along with a verbal explanation to provide a full picture of the study. All study participants were able to contact the master student directly using his contact details offered in the information sheet.

Informed consent refers to the process by which the participants are informed about the study and are assured about their rights in choosing whether or not they want to take part (Organization). An invitation letter and information sheet detailing the study was given to all potential participants to aid their decision making as to whether or not they wanted to participate. The information sheet 
also explained the broad purpose of the study, identified the researcher, and encouraged the participants to ask questions and seek clarification before making their final decision. In addition to the afore mentioned written information, the researcher explained the purpose of the research and assured potential participants their data would be strictly confidential indicating that it would only be used for the purposes specified. Once they decided to participate in the study, each participant was asked to sign a consent form, which they were given a copy of for their own record.

\subsubsection{Confidentiality}

Participant confidentiality was assured by assigning participant a number that would be used for all of their information in the quantitative strand of the study. Ethical principles incorporate confidentiality and the avoidance of deception.

Participants' identification should not be presented during the research stage (data collection, analysis or reporting study finding), thus the participants' information sheet stated clearly that the names of the participants would be treated confidentially.

Furthermore, all data was stored and kept securely and was only accessible by the research team. The computer software programme Statistical Package for Social Science (SPSS) stored information without features that could identify participants with the exception of their ID number, which was known only to the research team. In addition, participants were informed that their identity would not be revealed in any research report or documentation. The computer was also kept in a locked filing cabinet when it was not being used by other people.

\subsubsection{Full Disclosure}

Participants were given the information sheet, which had the full aims of the study and objectives. The information was used by either English or Arabic to be understood clearly by participants

\subsubsection{Beneficence}

The research assessed the expected benefit or risk that faced participants in the study. Potential benefits from this study included increasing our awareness about burnout and resilience that help to reduce burnout, effect of burnout on safety.

\subsubsection{Non-Malfeasance}

Researchers are expected to minimise potential harm or discomfort to study participants throughout the research process, including emotional upset, stress, fear of the study, financial harm.

\subsubsection{Self-Determination}

Participants have the right to participate voluntarily without any risk or penalty and the participants had the right to ask any question related to study nature, to refuse to give information, or to withdraw from the study at any point [34]. For 
this reason, at every part of the study, participants were advised that their participation was voluntary and that they could withdraw from it at any point with no explanation.

Table 1 describes the ethical principles addressed in the study.

\subsection{Data Management and Analysis}

\subsubsection{Quantitative Data Management}

Participant responses were first examined for missing raw data prior to data entry into the software analysis programme (SPSS version 23). In this study, the questionnaires had a mix of measures, including continuous variables and demographic variables such as gender and age. On the other hand, categorical variables was coded and treated as continuous variables.

\subsubsection{Quantitative Data Analysis}

Data obtained from participants were numerically coded and analysed using the SPSS for Windows, version 23. Descriptive statistics were used to summarise baseline characteristics, including socio-demographic and all variables.

\subsection{Summary}

The study on which this thesis is based on cross-sectional study survey assess nurses burnout, resilience and its association to safety culture.

\subsection{Inclusion Criteria}

- Registered Nurses (RN) must meet the following criteria for inclusion in this study:

- The RN should be working at Alamal \& Psychiatric Hospital in Jazan region

- The RN should be working on an inpatient unit and on an outpatient unit.

- The RN must have occupied the position for at least one year. Registered nurses with one year's post-qualifying experience. This allowed nurses to be oriented and informed about policy and work schedules at the hospitals

Table 1. Addressing ethical principles in the study.

\begin{tabular}{|c|c|}
\hline Ethical principles & How ethical principles were addressed in the study \\
\hline & $\begin{array}{l}\text { Master student translated the consent form from English to Arabic } \\
\text { to be understood by participants. }\end{array}$ \\
\hline Informed consent & $\begin{array}{l}\text { Master student explained the potential study objectives, } \\
\text { responsibilities, potential benefits and harms of taking part to } \\
\text { participants. }\end{array}$ \\
\hline Beneficence & $\begin{array}{l}\text { Benefits understanding and increasing nurses staff awareness about } \\
\text { burnout and resilience that help to reduce burnout, effect of burnout } \\
\text { on safety. }\end{array}$ \\
\hline Confidentiality & Each participant was assigned a number rather than a name. \\
\hline Self-determinatic & $\begin{array}{l}\text { Participants had the right to participate voluntarily in the study with } \\
\text { nno coercion and to withdraw from the study at any time without } \\
\text { providing justification. }\end{array}$ \\
\hline
\end{tabular}


- The RN must be healthy, not complaint from any physical problem or diseases.

\section{Reasons for choosing this research}

After working in a hospital for 10 years, I noticed that there was a considerable amount of burnout among nurses. I wanted to see how widespread this was among mental health nurses, and resilience as well as its effect on safety.

\section{Results}

\subsection{Introduction}

This chapter reports the result of the cross-sectional study about the level of burnout, resilience and its association to safety culture. The chapter also describes baseline socio-demographic data of the study participants.

This paper is meant to address the concept of nursing burnout. This is an analysis and results section of the paper that shows how different factors within the nursing domain have an effect on nurse burnout. The descriptive statistics is important, as it will try to show various relationships that exist between the nurses and different factors as far as the burnouts are concerned. This chapter presents the results of this quantitative study. In this chapter, descriptive statistics have been used to describe the data and sample. These statistics includes frequencies, percentages, mean, standard deviation, minimum, and maximum.

Table 2 reveals the characteristics of the study participants.

Table 2 below illustrates the all demographic data for participants which include for example age, gender, and type of shift. The table also explains the number and percentage for each variable.

Table 2. Baseline demographic characteristics of sample.

\begin{tabular}{|c|c|c|c|}
\hline & & $\mathrm{n}$ & Percent \\
\hline & $20-29$ years & 54 & 44.3 \\
\hline \multirow[t]{2}{*}{ Age } & $30-39$ years & 61 & 50.0 \\
\hline & 40 - more & 4 & 3.3 \\
\hline \multirow{2}{*}{ Gender } & Male & 71 & 58.2 \\
\hline & Female & 48 & 39.3 \\
\hline \multirow{2}{*}{ Marital status } & single & 35 & 28.7 \\
\hline & married & 84 & 68.9 \\
\hline \multirow{3}{*}{ Monthly income } & $5000-10000$ & 43 & 35.2 \\
\hline & $10000-15000$ & 63 & 51.6 \\
\hline & 15000-more & 13 & 10.7 \\
\hline \multirow{3}{*}{ Level of education } & diploma & 64 & 52.5 \\
\hline & bachelor & 49 & 40.2 \\
\hline & Master or more & 6 & 4.9 \\
\hline
\end{tabular}


Continued

\begin{tabular}{|c|c|c|c|}
\hline & $1-4$ & 50 & 41.0 \\
\hline \multirow[t]{3}{*}{ Years of experience } & $5-10$ & 38 & 31.1 \\
\hline & 11 - more & 31 & 25.4 \\
\hline & $\mathrm{D}$ & 44 & 36.1 \\
\hline \multirow[t]{5}{*}{ Type of shift work } & EN & 39 & 32.0 \\
\hline & Rotation & 36 & 29.5 \\
\hline & Acute & 42 & 34.4 \\
\hline & Chromic & 23 & 18.9 \\
\hline & Addiction & 13 & 10.7 \\
\hline \multirow[t]{4}{*}{ Department } & ER & 25 & 20.5 \\
\hline & OPD & 7 & 5.7 \\
\hline & Other & 9 & 7.4 \\
\hline & Acute & 42 & 34.4 \\
\hline \multirow{3}{*}{$\begin{array}{c}\text { The average Number of } \\
\text { patients assigned to } \\
\text { nurse }\end{array}$} & $1-5$ & 43 & 35.2 \\
\hline & $6-10$ & 46 & 37.7 \\
\hline & 11 - more & 30 & 24.6 \\
\hline \multirow{2}{*}{ Nationality } & Saudi & 97 & 79.5 \\
\hline & Non-Saudi & 22 & 18.0 \\
\hline \multirow{2}{*}{ Residence } & Jazan & 110 & 90.2 \\
\hline & Other & 9 & 7.4 \\
\hline $\begin{array}{l}\text { Do you have the plan to } \\
\text { leave the psychiatric }\end{array}$ & Yes & 46 & 37.7 \\
\hline hospital & No & 73 & 59.8 \\
\hline
\end{tabular}

As can be seen from the table, a significant 61 individuals with $50 \%$ who aged between 30 - 39 years were participated in this study followed by 54 participants from 20 - 29 age group of $44.3 \%$ as to were 4 participants $3.3 \%$ from the age group of 40 and more. When it comes to gender, number of male participants was higher than that of their female counterparts, which was at 71 with $58.2 \%$, and 48 with $39.3 \%$ respectively. At same time, there was an exponential 84 individual who got married were participated in this study, the singles was just 35 in number again with $28.7 \%$. Interestingly, the monthly income of respondents varied from 5000 - 15,000 in which only 13 personnel were receiving 1500 more. While considering the educational status of the surveyors a great majority had completed diploma was 64 followed by 49 individuals who had been completed bachelor's degree $40 \%$ - 2\% however, only 6 staffs were qualified with master's degree or more during this survey period. Noticeably while 50 individuals $41 \%$ had 4 years of working experience. Considerably, more than 30 personnel's $25.4 \%$ had the highest working experience than that of other at 11 years. In the 
case of, type of shift work, 44 staff opined for day shift, which was remarkably higher than that of staff opted for $\mathrm{E} / \mathrm{N}$ and rotation with 39 and 36 numbers respectively. During the survey period, there were similar number of staffs were posted in acute 1 and acute 2 was 42 with the percentage of $34.4 \%$. whereas the number of staffs in ER and chronic was around 24, with percentage of 19.5\%. in contrast, while only 13 staffs were working in addiction, 7 were posted in OPD and other departments were recorded only 9 staffs by the given period. While considering the patient nurse ratio, 46 staffs were assigned for 6 - 10 patients, 43 staffs were assigned for 1 - 5 patients, and 11 and more patients were assigned to only 30 staff considerably percentage of $24.6 \%$. Ranging $79.5 \%$ had been working in that organization 97 native individuals. The number of non-Saudi staffs were only 22 with $18 \%$. Among the respondents, a vast majority were residing in Jazan with $90.2 \%$ only a coverage of $7.4 \%$ from other areas. In the case of individual future plan, around 73 participants of $59.8 \%$ did not have the plan to leave the psychiatric hospital. Whereas 46 personnel of $37.7 \%$ were interested to move from this hospital.

Table 3 shows various analysis of burnout among nurses. The major factors that have been considered include emotional exhaustion, personal accomplished, depersonalization, safety, teamwork, safety climate, job satisfaction, management perception, work condition, and resilience. Based on the above-named metrics, nursing burnout is directly linked with above-named factors. The maximum number of burnout resulting from emotional exhaustion was 57 while the minimum number was 18 . On the other hand, the maximum number of burnouts resulting from personal accomplished was 43 while the minimum number was 6 . With regard to depersonalization sector, out of 119 sample, the maximum number was 30 while the minimum number was 12 .

Table 3. Burnout, resilience and safety.

\begin{tabular}{cccccc}
\hline & N & Minimum & Maximum & Mean & Std. Deviation \\
\hline Burnout & & & & & \\
\hline Emotional Exhaustion & 119 & 18.0 & 57.0 & 39.874 & 8.7047 \\
Personal Accomplished & 119 & 6.0 & 43.0 & 24.378 & 9.6866 \\
Depersonalization & 119 & 12.0 & 30.0 & 21.454 & 3.6073 \\
\hline Safety & & & & & \\
\hline Teamwork & 119 & 6.0 & 30.0 & 21.025 & 6.2875 \\
safety climate & 119 & 7.0 & 35.0 & 24.538 & 7.3977 \\
job satisfaction & 119 & 5.0 & 25.0 & 19.824 & 4.7132 \\
management perception & 119 & 10.0 & 50.0 & 36.143 & 11.0900 \\
work condition & 119 & 4.0 & 19.0 & 12.748 & 4.3144 \\
\hline Resilience & & & & & \\
\hline & 119 & 1.0 & 100.0 & 77.101 & 24.9543 \\
\hline
\end{tabular}


With regard to safety, there were no issues connected to burnout. With regard to the teamwork, the minimum number was 6.0 while the maximum number was 30 . With regard to safety climate, the maximum number was 35 while the minimum number was 7 . In terms of job satisfaction, the minimum number is five while the maximum number was 25 . In terms of management perception, the minimum number was ten while the maximum number of burnouts was 50 . With regard to work condition, the minimum number was 4 while the maximum number was 19 . With regard to resilience, the minimum number was 1 while the maximum number was 100 . Therefore, those factors leading to burnouts reported the highest means apart from resilience. Therefore, it is worth to note that resilience is one of the factors that is used to reduce burnouts. At the same time, factors that usually address burnouts safety climate, job satisfaction, management perception, and work condition reported the lowest means since nursing burnout does not occur under such conditions.

\subsection{Correlation Analysis}

Table 4 shows correlation analysis between the different variables that were used in our research. Such variables include burnout, emotional accomplishment and personal accomplishment. With the rule that the significant value is $\mathrm{p} \leq 0.05$, it is clear that most of the correlations that existed between the variable used were not significant. However, the significant correlations between the variables as shown below

The table below, it is clear that there exist some significant correlations between different variables. An example is the existence of negative correlation between exhaustion and teamwork, job satisfaction, management perception and work conditions. There is also strong positive correlation between job satisfaction with management perception, job satisfaction and working conditions as evident from Table 3.

Table 4 shows Pearson correlation coefficient was used to measure the relationship between dependent variables and demographic data of the respondents.

1) The p-values (Sig.) are larger than $\alpha=0.05$, and the $r$-calculated values are less than the r-tabled value $=0.169$ for the three fields; "Burnout, Resilience, and Safety culture". So it can be said that there is no significant correlation between the demographic field "Age" and the fields; "Burnout, Resilience, and Safety culture".

2) The p-values (Sig.) are larger than $\alpha=0.05$, and the $r$-calculated values are less than the r-tabled value $=0.169$ for the two fields; "Burnout and Safety Attitude Culture". whilst the p-value (Sig.) is less than $\alpha=0.05$, and the r-calculated value is larger than the $\mathrm{r}$-tabled value $=0.169$ for the fields; "Resilience". So it can be said that there is a significant correlation between the demographic field "Gender" and the "Resilience", and there is no significant correlation between the demographic field "Gender" and the two fields; "Burnout and Safety Attitude Culture". 
Table 4. Burnout, resilience and safety correlation.

\begin{tabular}{|c|c|c|c|c|c|c|c|c|c|c|}
\hline \multirow{2}{*}{\multicolumn{2}{|c|}{ Demographic Data }} & \multirow[b]{2}{*}{$\mathrm{EE}$} & \multicolumn{2}{|c|}{ Burnout } & \multirow[t]{2}{*}{ Resilience } & \multicolumn{5}{|c|}{ Safety Culture } \\
\hline & & & PA & DP & & TW & SC & JS & MP & WC \\
\hline \multirow{2}{*}{ Age } & Pearson Correlation & 0.035 & -0.017 & 0.055 & 0.52 & -0.60 & -0.72 & -0.51 & -0.56 & -0.41 \\
\hline & Sig. (2-tailed) & 0.702 & 0.851 & 0.554 & 0.577 & 0.520 & 0.438 & 0.583 & 0.547 & 0.660 \\
\hline \multirow{2}{*}{ Gender } & Pearson Correlation & -0.056 & 0.101 & -0.119 & 0.186 & -0.060 & -0.072 & -0.051 & -0.056 & -0.041 \\
\hline & Sig. (2-tailed) & 0.546 & 0.276 & 0.196 & 0.043 & 0.501 & 0.404 & 0.542 & 0.289 & 0.386 \\
\hline \multirow{2}{*}{ Marital status } & Pearson Correlation & 0.036 & -0.098 & 0.069 & 0.033 & -0.039 & -0.030 & -0.005 & -0.027 & -0.034 \\
\hline & Sig. (2-tailed) & 0.699 & 0.289 & 0.456 & 0.721 & 0.677 & 0.742 & 0.960 & 0.773 & 0.717 \\
\hline \multirow{2}{*}{ Monthly income } & Pearson Correlation & 0.161 & -0.180 & 0.254 & 0.055 & -0.118 & -0.148 & -0.152 & -0.179 & -0.152 \\
\hline & Sig. (2-tailed) & 0.080 & 0.050 & 0.005 & 0.551 & 0.200 & 0.108 & 0.098 & 0.052 & 0.099 \\
\hline \multirow{2}{*}{ Level of education } & Pearson Correlation & -0.131 & 0.027 & -0.154 & 0.091 & 0.078 & 0.095 & 0.099 & 0.083 & 0.087 \\
\hline & Sig. (2-tailed) & 0.155 & 0.772 & 0.094 & 0.327 & 0.398 & 0.305 & 0.284 & 0.372 & 0.346 \\
\hline \multirow{2}{*}{ Years of experience } & Pearson Correlation & 0.105 & -0.051 & 0.219 & 0.014 & -0.155 & -0.169 & -0.136 & -0.164 & -0.142 \\
\hline & Sig. (2-tailed) & 0.256 & 0.585 & 0.017 & 0.878 & 0.092 & 0.066 & 0.141 & 0.075 & 0.123 \\
\hline \multirow{2}{*}{ Type of shift work } & Pearson Correlation & -0.194 & -0.007 & -0.124 & 0.012 & 0.314 & 0.338 & 0.341 & 0.325 & 0.323 \\
\hline & Sig. (2-tailed) & 0.035 & 0.940 & 0.180 & 0.898 & 0.001 & 0.000 & 0.000 & 0.000 & 0.000 \\
\hline \multirow{2}{*}{ Department } & Pearson Correlation & -0.255 & -0.010 & -0.130 & 0.037 & 0.292 & 0.313 & 0.334 & 0.298 & 0.320 \\
\hline & Sig. (2-tailed) & 0.005 & 0.912 & 0.159 & 0.691 & 0.001 & 0.001 & 0.000 & 0.001 & 0.000 \\
\hline \multirow{2}{*}{$\begin{array}{l}\text { The average Number of } \\
\text { patients assigned to nurse }\end{array}$} & Pearson Correlation & -0.037 & 0.087 & -0.009 & -0.070 & 0.054 & 0.069 & 0.055 & 0.047 & 0.077 \\
\hline & Sig. (2-tailed) & 0.686 & 0.349 & 0.919 & 0.449 & 0.558 & 0.455 & 0.554 & 0.612 & 0.402 \\
\hline \multirow{2}{*}{ Nationality } & Pearson Correlation & 0.137 & -0.104 & 0.074 & -0.060 & -0.244 & -0.258 & -0.240 & -0.267 & -0.274 \\
\hline & Sig. (2-tailed) & 0.138 & 0.261 & 0.423 & 0.515 & 0.008 & 0.005 & 0.008 & 0.003 & 0.003 \\
\hline \multirow{2}{*}{ Residence } & Pearson Correlation & -0.238 & -0.026 & -0.112 & -0.010 & 0.187 & 0.208 & 0.234 & 0.209 & 0.224 \\
\hline & Sig. (2-tailed) & 0.009 & 0.779 & 0.227 & 0.913 & 0.042 & 0.023 & 0.010 & 0.022 & 0.014 \\
\hline $\begin{array}{l}\text { Do you have the plan } \\
\text { to leave the psychiatric }\end{array}$ & Pearson Correlation & 0.098 & 0.315 & -0.088 & 0.144 & -0.220 & -0.197 & -0.250 & -0.138 & -0.119 \\
\hline hospital & Sig. (2-tailed) & 0.290 & 0.000 & 0.341 & 0.119 & 0.016 & 0.031 & 0.006 & 0.134 & 0.198 \\
\hline
\end{tabular}

**. Correlation is significant at the 0.01 level (2-tailed). ${ }^{*}$. Correlation is significant at the 0.05 level (2-tailed). c. Cannot be computed because at least one of the variables is constant.

3) The p-values (Sig.) are larger than $\alpha=0.05$, and the $r$-calculated values are less than the $r$-tabled value $=0.169$ for the three fields; "Burnout, Resilience, and Safety culture". So it can be said that there is no significant correlation between the demographic field "Marital Status" and the fields; "Burnout, Resilience, and Safety culture".

4) The p-values (Sig.) are less than $\alpha=0.05$, and the $r$-calculated values are larger than the r-tabled value $=0.169$ for the two parts; "Personal Accomplishment and Depersonalization" of the field "Burnout". Whilst the p-value (Sig.) is larger than $\alpha=0.05$, and the $r$-calculated value is less than the $r$-tabled value $=$ 
0.169 for the fields; "Emotional of Burnout, Resilience, and Safety culture". So it can be said that there is a significant correlation between the demographic field "Monthly Income" and the two parts "Personal Accomplishment and Depersonalization" of the field "Burnout", and there is no significant correlation between the demographic field "Monthly Income" and the fields "Emotional of Burnout, Resilience, and Safety culture".

5) The p-values (Sig.) are larger than $\alpha=0.05$, and the $r$-calculated values are less than the $r$-tabled value $=0.169$ for the three fields; "Burnout, Resilience, and Safety culture". So it can be said that there is no significant correlation between the demographic field "Level of Education" and the fields; "Burnout, Resilience, and Safety culture".

6) The p-values (Sig.) are less than $\alpha=0.05$, and the $r$-calculated values are larger than the r-tabled value $=0.169$ for the part; "Depersonalization" of the field "Burnout". whilst the p-value (Sig.) is larger than $\alpha=0.05$, and the r-calculated value is less than the r-tabled value $=0.169$ for the fields; "Emotional and Personal Accomplishment of Burnout, Resilience, and Safety culture". So it can be said that there is a significant correlation between the demographic field "Years of Experience" and the two parts "Personal Accomplishment and Depersonalization" of the field "Burnout", and there are no significant correlation between the demographic field "Years of Experience" and the fields "Emotional and Personal Accomplishment of Burnout, Resilience, and Safety culture".

7) The p-values (Sig.) are less than $\alpha=0.05$, and the $r$-calculated values are larger than the r-tabled value $=0.169$ for the two fields; "Emotional of Burnout and Safety Attitude Culture". whilst the p-value (Sig.) is larger than $\alpha=0.05$, and the $\mathrm{r}$-calculated value is less than the $\mathrm{r}$-tabled value $=0.169$ for the fields; "Resilience", and the two parts; "Type of Shift Work" and the "Personal Accomplishment and Depersonalization of the field "Burnout". So it can be said that there is a significant correlation between the demographic field "Type of Shift Work" and the fields "Emotional of Burnout and Safety Attitude Culture", and there is no significant correlation between the demographic field "Type of Shift Work" and the fields "Resilience", and the two parts; and the "Personal Accomplishment and Depersonalization of the field "Burnout".

8) The p-values (Sig.) are less than $\alpha=0.05$, and the $r$-calculated values are larger than the r-tabled value $=0.169$ for the two fields; "Emotional part of Burnout and Safety Attitude Culture". whilst the p-value (Sig.) is larger than $\alpha=$ 0.05 , and the $r$-calculated value is less than the $r$-tabled value $=0.169$ for the fields; "Resilience", and the two parts; "Personal Accomplishment and Depersonalization" of the field "Burnout". So it can be said that there is a significant correlation between the demographic field "Department" and the fields "Emotional part of Burnout and Safety Attitude Culture", and there is no significant correlation between the demographic field "Department" and the fields "Resilience", and the two parts; "Personal Accomplishment and Depersonalization of the field "Burnout". 
9) The p-values (Sig.) are larger than $\alpha=0.05$, and the $r$-calculated values are less than the r-tabled value $=0.169$ for the three fields; "Burnout, Resilience, and Safety culture". So it can be said that there is no significant correlation between the demographic field "Average Number of Patients Assigned to Nurse" and the fields; "Burnout, Resilience, and Safety culture".

10) The p-values (Sig.) are larger than $\alpha=0.05$, and the $\mathrm{r}$-calculated values are less than the r-tabled value $=0.169$ for the two fields; "Burnout and Resilience". whilst the p-value (Sig.) is less than $\alpha=0.05$, and the $\mathrm{r}$-calculated value is larger than the $\mathrm{r}$-tabled value $=0.169$ for the field "Resilience". So it can be said that there is a significant correlation between the demographic field "Nationality" and the field "Resilience", and there is no significant correlation between the demographic field "Nationality" and the two fields; "Burnout and Resilience".

11) The p-values (Sig.) are less than $\alpha=0.05$, and the $r$-calculated values are larger than the $r$-tabled value $=0.169$ for the two fields; "Emotional part of Burnout and Safety Attitude Culture". whilst the p-value (Sig.) is larger than $\alpha=$ 0.05 , and the $\mathrm{r}$-calculated value is less than the $\mathrm{r}$-tabled value $=0.169$ for the fields; "Resilience", and the two parts; "Type of Shift Work" and the "Personal Accomplishment and Depersonalization of the field "Burnout". So it can be said that there is a significant correlation between the demographic field "Residence" and the fields "Emotional part of Burnout and Safety Attitude Culture", and there is no significant correlation between the demographic field "Residence" and the fields "Resilience", and the two parts; "Personal Accomplishment and Depersonalization" of the field "Burnout".

12) The p-values (Sig.) are less than $\alpha=0.05$, and the $\mathrm{r}$-calculated values are larger than the $r$-tabled value $=0.169$ for the; "Personal Accomplishment part of Burnout field and Teamwork, Safety Climate, and Job Satisfaction parts of Safety Attitude Culture field". whilst the p-value (Sig.) is larger than $\alpha=0.05$, and the $r$-calculated value is less than the $r$-tabled value $=0.169$ for the fields; "Resilience", the two parts; "Management Perception and Work Conditions" of the field "Safety Attitude Culture" and the two parts; "Emotional and Depersonalization" of the field "Burnout". So it can be said that there is a significant correlation between the demographic field "Do you have the plan to leave the psychiatric hospital" and the fields "Personal Accomplishment of Burnout and Teamwork, Safety Climate, and Job Satisfaction of Safety Attitude Culture", and there is no significant correlation between the demographic field "Do you have the plan to leave the psychiatric hospital" and the fields "Resilience", the two parts; "Emotional" and the "Depersonalization of the field "Burnout" and the two parts; "Management Perception and Work Conditions" of the field "Safety Attitude Culture".

\section{Discussion}

\subsection{Introduction}

The overall aim of this study was to assess nurse's burnout, resilience and its as- 
sociation to safety culture life. This chapter discusses the findings in relation to the existing research evidence by comparing and contrasting similarities and differences between the results reported in the current study with those reported elsewhere, whilst also empirically, theoretically and pragmatically analysing the results. In addition, the strengths and limitations of the current study are discussed. The implications of this study finding for mental health practice, education, research and management in Saudi Arabia were also presented in the chapter. The chapter ends with recommendations for the future in each of these areas and presents the conclusions of the study.

\subsection{The Demographic Characteristics Data}

As presented in the table, there was a significant increase in the number of participants between the age group of 30 - 39 while comparing to gender it is clear from the data that the male showed two-fold increase in percentage of participation. It is apparently seen that $68.9 \%$ of married participants were involve in the study. We can see that the employees who are receiving monthly income of 10 15 thousand were noticeably $51.6 \%$. It is obvious that a large proportion of $52.5 \%$ of diploma candidates given their opinion. Subsequently the nursing staff with more than 11years experience was fewer than the staff with less experience the data suggests that almost equal percentage of staffs from each shifts responded in the survey which hovered around $32 \%$. It is interesting to note that there was an equal percentage of respondents were from Acute wards (34.4\%.) Now turning to the details regarding the average number of patients assigned to nurse, 30 staffs who were responsible for 11 or more patients quoted their opinion which is around $24.6 \%$ not has high as in other two groups. It is interesting to note that substantial number of 97 participants with $79.5 \%$ actively observed that an over whelming $90.2 \%$ of respondents were from Gazan. It is conspicuous that a great majority of $59.5 \%$ of staffs who participated in this survey were not interested to leave the psychiatric hospital.

\subsection{Overview of Main Findings}

The study findings suggest that there is no significant correlation between demographical field such as age, marital status, education, number of patient and nationality with the resilience and other two fields burnout and safety attitude culture. So it can be said that there is a significant correlation between the demographical field monthly Income and experience and the two parts personal accomplishment and depersonalization of the field burnout and there is no significant correlation between the fields of emotional of burnout, resilience and safety culture. The study results show that there is a significant correlation between demographic field gender and the resilience and there is no significant correlation between the demographic field gender and the two fields burnout and safety attitude culture. According to the survey findings there is a significant correlation between the demographic fields resilience and shift work and the 
fields emotional parts of burnout and safety attitude culture, and there is no significant correlation between the other fields/ resilience and the two parts personal accomplishment and depersonalization of the fields burnout, as per the study shows there is a significant correlation between the demographic field department and the fields resilience, emotional part of burnout and safety attitude culture where as demographic fields exit has significant correlation only in the fields of depersonalization of the field burnout and the safety attitude culture.

Overall, this study offers a unique perspective in the assessment of nurses' burnout, resilience and safety culture among mental health nurses working in Al-Amal \& Psychiatric Hospital, Jazan in KSA. In addition, this study has individually analyzed each nurse characteristic to further understand possible predictors of burnout and impact on their performance as healthcare providers. The findings in this study revealed that nurse burnout in mental healthcare for nurses working with psychiatric patients is relatively high. For instance, about a third of the respondents claimed that they wished to leave their current organizations due to work-related stress and burnout. In healthcare organizations, the inability to address hospital errors supports worker burnout, which further leads to job dissatisfaction (Hall, Johnson, Watt, T'Sipa \& O'Connor, 2016) [37]. The inability to deal with hospital errors is also outlined in the findings, which indicate that the high number of nurses interviewed did not agree with the proposition that they receive appropriate feedback about their performance. According to Cusack et al. (2016) [38], some of the factors that contribute to healthcare worker resilience building include work feedback and staff support.

On the other hand, although a high number of nurses like challenges in their jobs, some of the nurses reported that challenges diminish their motivation and discourage them from meeting their obligations. The findings of this study coincide with some of the already available knowledge that nurses experience burnout when they have to start new practices or launch their careers (Dyrbye et al., 2014) [39]. The study findings indicate that when nurses were asked if their career is received well in clinical care, only $24 \%$ strongly agreed while the rest slightly agreed or disagreed with this reservation. The finding that a high number of nurses do not believe that their nursing careers may be hardening them emotionally is a sure indication that nurse reliance is of importance and if healthcare organizations do not promote activities and the environment that support it, it may be impossible to maintain high standards of care. By definition, quality is the standard necessary for a product or service provider to meet customer needs (Ghahramanian et al., 2017) [40]. In the absence of a supportive environment and emotional resilience, quality care is not guaranteed as indicated in this study.

According to the nurses interviewed, many of them are assigned more than five patients per shift, a high number of them feel used after a typical workday a few times in a month or year and their work is frustrating. Reduction of work effort and turnover result from work frustration (Dyrbye et al., 2017 [18] [41]). 
The indications from this study support that work frustration due to high numbers of patients attended to in a single shift and frustrations is related to work roles and responsibilities. These findings may go a long way in improving the wellbeing and burnout levels of mental health nurses, thereby enabling them to provide better patient care.

\subsection{Strengths and Limitations}

Strengths, to the best of our knowledge, this is the first study that has to assess nurses burnout, resilience and its association to safety culture at mental health hospital field. The application of the MBI, which is a standardized means of measuring burnout that has been interpreted into various languages and used in countries throughout the world, was helpful in eliciting burnout among Saudi nurses working in acute psychiatric care.The participants in the current research were recruited from Alamal \& Psychiatric Hospital at Jazan, Saudi Arabia. The current study report strengthening the reporting observational studies in epidemiology tool was administered to assess the study report quality. Although this study rated as good quality, it has several

limitations. First, all the study sample nurses only at one hospital. Further study needs to be conducted and included more nurses from various region and another hospital. Second, power calculation revealed that 119 participants are needed to be adequately powered. Third, the researcher work at same hospital. However, the time constraint of the master program was a barrier to recruit larger number. Third, the current study was planned to take place in different hospital in Jazan. However, delay in receiving ethical approval from the Ministry of Health enforced us to recruit participants from Alamal \& psychiatric hospital at Jazan solely.

\subsection{Study Implication}

\subsubsection{Implications for the Future Research}

This research has raised many questions in need of further investigation. Thus, further work needs to be done to establish the prevention programme for burnout and learning coping mechanism. Future research needs to examine more closely the effect of burnout on quality of care and work environment.

This research is very much the start of a continuing research programme. Given the diversity of Saudi culture there are a number of studys that could be undertaken to better understand the difficulties inherent in nursing within the KSA. For example, issues of burnout and its prevention for males and females needs further exploration. Examining the direct effects of burnout prevention programs on services (hospitals), those delivering nursing care, teamwork and service users are all worthwhile projects that would promote a better understanding of healthcare in SA.

\subsubsection{Unique Contribution of This Research}

This research study provides important information regarding the level of bur- 
nout, resilience and its effect on patient safety experienced by mental health nurses working in Alamal \& psychiatric hospital in Saudi Arabia. This unique finding has important implications for nurses and the organizations who employ them. It requires further research as to what could be done to sustain the decrease in burnout and to measure the effects of such interventions in terms of personal, organizational and patient costs.

\subsubsection{Dissemination Plan}

The motivation for this study was to examine the nurses burnout, resilience and its association on safety culture. In order to raise awareness regarding the burnout and its effectiveness, a report of the findings will be dispatched to the Saudi $\mathrm{MOH}$. This will be followed up via a meeting with the director of the General Directorate of Health Affairs in Jazan S.A to discuss the inferences of the study and how the findings could be transposed into an action plan for practice. In addition, findings will be disseminated via local, national and international presentations. I also plan to publish at least one paper from this study in the hope that it will benefit future studies.

\subsection{Conclusions}

Briefly, it can be concluded that nursing burnouts are not only an organizational challenge but also a global challenges that affect nurses. However, with resilience measures being put in place, the notion of nursing burnouts among the nurses is likely to reduce. However, the means of administration of the resilience measures should be based on the nature of work each nurse is subjected to. Such a measure is likely to make sure that the issue to do with nursing burnout is mitigated from taking place.

To make sure burnout among nurses is reduced, nurses and other stakeholders in the healthcare domain should be in a position to understand the role of resilience measures in curbing nursing burnouts. Resilience measures should be adopted by nurses and healthcare organizations to make sure the welfare of nurses is well met to make sure at the long turn nursing burnout is avoided. The search for long-lasting solutions is the sole solution towards eliminating the menace. By improving working conditions and safety, it is regarded as one of the best methods that organizations should do to make sure the menace of nursing burnout is eliminated. Based on reviews from various case study such as the one carried the literature review have tried to capture in China, nursing burnout is one of the global issues affecting nurses.

This study established that nurse burnout in mental healthcare institutions for the nurses working with psychiatric patients is evident. The information from this study that burnout is a common issue among healthcare providers in Saudi Arabia should act as a wakeup call for healthcare leaders and governments to re-establish their interest in this matter and address all the causes and effects. This empirical evidence represents the opinions of many nurses working in mental healthcare institutions and indicates that working with psychiatric pa- 
tients reduces increases the possibility of burnout. One of the recommendations from this study is to focus on the length of shifts and number of patients assigned to nurses during each shift. The longer the shifts and the higher the number of patients a nurse attends to, the higher the burnout and the lower the resilience, which in turn hinders safety culture. Additionally, from the results, healthcare organizations should seek to support staff to minimize their possibilities to seek newer job opportunities. Supporting employees and improving the workplace environment promotes worker resilience and enables them to keep stress on manageable levels. However, the failure to support staff, offer feedback for performance and appreciate the role of nursing in clinical care diminishes nurse resilience and promotes burnout to influence safety culture negatively.

From the analysis that has been carried out, it has emerged that nursing burnout is one of the problems many nurses go through. Numerous various factors contribute to the problem. Most of the factors are as a result of age, gender, marital status, region, work placement among others. From the analysis, it can be deduced that most nurses who suffer burnouts are mostly those who have a lot of commitment such as married ones and those who might be having too much workload such as diploma holders.

To avoid nursing burnouts, there are measures that need to be implemented. One of the measures is adherence to resilience measures that are meant to ensure the welfare of nurses is met. For instance, measures such as physical exercises and counseling are some of the measures healthcare institutions should consider undertaking so that the nurses are able to experience a reduced rate of burnouts.

Another method to ensure the rate of burnout among nurses is reduced is by making sure nurses are able to have the good working condition. A working condition whereby nurses have a shift that is rotational is one of the solutions that should be considered in order to reduce fatigue and stress among nurses that result in burnouts.

\section{Conflicts of Interest}

The author declares no conflicts of interest regarding the publication of this paper.

\section{References}

[1] Ulrich, B. and Kear, T. (2014) Patient Safety and Patient Safety Culture: Foundations of Excellent Health Care Delivery. Nephrology Nursing Journal, 41, 447-456.

[2] Twigg, D. and Attree, M. (2013) Patient Safety: Committing to Learn and Acting to Improve. Nurse Education Today, 34, 159-161. https://doi.org/10.1016/j.nedt.2013.11.002

[3] Van Bogaert, P., Kowalski, C., Weeks, S.M. and Clarke, S.P. (2013) The Relationship between Nurse Practice Environment, Nurse Work Characteristics, Burnout and Job Outcome and Quality of Nursing Care: A Cross-Sectional Survey. International Journal of Nursing Studies, 50, 1667-1677. 
https://doi.org/10.1016/j.ijnurstu.2013.05.010

[4] Karanikola, M., Giannakopoulou, M., Mpouzika, M., Kaite, C.P., Tsiaousis, G.Z. and Papathanassoglou, E.D. (2015) Dysfunctional Psychological Responses among Intensive Care Unit Nurses: A Systematic Review of the Literature. Revista da Escola de Enfermagem da USP, 49, 847-857. https://doi.org/10.1590/S0080-623420150000500020

[5] Farahat, T.M., Hegazy, N.N. and Mohamed, D.H. (2016) Burnout among Physicians in Qalubia Primary Health Care Facilities, Egypt. Journal of Family Medicine and Health Care, 2, 1-5. https://doi.org/10.11648/j.jfmhc.20160201.11

[6] Zou, G., Shen, X., Tian, X., Liu, C., Li, G., Kong, L. and Li, P. (2016) Correlates of Psychological Distress, Burnout, and Resilience among Chinese Female Nurses. Industrial Health, 54, 389-395. https://doi.org/10.2486/indhealth.2015-0103

[7] Schmidt, M. and Haglund, K. (2017) Debrief in Emergency Departments to Improve Compassion Fatigue and Promote Resiliency. Journal of Trauma Nursing, 24, 317-322. https://doi.org/10.1097/JTN.0000000000000315

[8] Yeun, Y.R. and Han, J.W. (2016) Effect of Nurses' Organizational Culture, Workplace Bullying and Work Burnout on Turnover Intention. International Journal of BioScience and Bio-Technology, 8, 372-380. https://doi.org/10.14257/ijbsbt.2016.8.1.33

[9] Al Suliman, B.K. and Al Hablani, M.N. (2014) Burnout among Nurses in Tabuk Military Hospital. International Journal of Medical Science and Public Health, 3, 540-545. https://doi.org/10.5455/ijmsph.2014.250220143

[10] Rushton, C.H., Batcheller, J., Schroeder, K. and Donohue, P. (2015) Burnout and Resilience among Nurses Practicing in High-Intensity Settings. American Journal of Critical Care, 24, 412-420. https://doi.org/10.4037/ajcc2015291

[11] Tuna, R. and Baykal, Ü. (2014) The Relationship between Job Stress and Burnout Levels of Oncology Nurses. Asia-Pacific Journal of Oncology Nursing, 1, 33-39. https://doi.org/10.4103/2347-5625.135818

[12] Braithwaite, J., Wears, R.L. and Hollnagel, E. (2015) Resilient Health Care: Turning Patient Safety on Its Head. International Journal for Quality in Health Care, 27, 418-420. https://doi.org/10.1093/intqhc/mzv063

[13] Chitura, D. and Chitura, M. (2014) Burnout Syndrome in Intensive Care Unit Nurses in Zimbabwe. European Scientific Journal, 10, 436-457.

[14] Ibikunle, P., Amah, E. and Useh, U. (2016) Prevalence and Pattern of Burnout Syndrome among Healthcare Professionals in a University Teaching Hospital. Tropical Journal of Medical Research, 19, Article No. 144. https://doi.org/10.4103/1119-0388.185443

[15] Morse, G., Salyers, M.P., Rollins, A.L., Monroe-DeVita, M. and Pfahler, C. (2012) Burnout in Mental Health Services: A Review of the Problem and Its Remediation. Administration and Policy in Mental Health and Mental Health Services Research, 39, 341-352. https://doi.org/10.1007/s10488-011-0352-1

[16] Abdo, S.A., El-Sallamy, R.M., El-Sherbiny, A.A. and Kabbash, I.A. (2016) Burnout among Physicians and Nursing Staff Working in the Emergency Hospital of Tanta University, Egypt. Eastern Mediterranean Health Journal, 21, 906-915. https://doi.org/10.26719/2015.21.12.906

[17] Wong, A.V.K. and Olusanya, O. (2017) Burnout and Resilience in Anaesthesia and Intensive Care Medicine. BJA Education, 17, 334-340. https://doi.org/10.1093/bjaed/mkx020

[18] Dall'Ora, C., Griffiths, P., Ball, J., Simon, M. and Aiken, L.H. (2015) Association of 
$12 \mathrm{~h}$ Shifts and Nurses' Job Satisfaction, Burnout and Intention to Leave: Findings from a Cross-Sectional Study of 12 European Countries. BMJ Open, 5, Article ID: e008331. https://doi.org/10.1136/bmjopen-2015-008331

[19] Profit, J., Sharek, P.J., Amspoker, A.B., Kowalkowski, M.A., Nisbet, C.C., Thomas, E.J., et al. (2014) Burnout in the NICU Setting and Its Relation to Safety Culture. BMJ Quality \& Safety, 23, 806-813. https://doi.org/10.1136/bmjqs-2014-002831

[20] Boardman, L. (2016) Building Resilience in Nursing Students: Implementing Techniques to Foster Success. International Journal of Emergency Mental Health and Human Resilience, 18, 1-5. https://doi.org/10.4172/1522-4821.C1.005

[21] Loeppke, R., Boldrighini, J., Bowe, J., Braun, B., Eggins, E., Eisenberg, B.S., et al. (2017) Interaction of Health Care Worker Health and Safety and Patient health and Safety in the US Health Care System: Recommendations from the 2016 Summit. Journal of Occupational and Environmental Medicine, 59, 803-813. https://doi.org/10.1097/JOM.0000000000001100

[22] Gilmartin, H., Goyal, A., Hamati, M.C., Mann, J., Saint, S. and Chopra, V. (2017) Brief Mindfulness Practices for Healthcare Providers-A Systematic Literature Review. The American Journal of Medicine, 130, 1219.E1-1219.E17. https://doi.org/10.1016/j.amjmed.2017.05.041

[23] Tawfik, D.S., Phibbs, C.S., Sexton, J.B., Kan, P., Sharek, P.J., Nisbet, C.C., et al. (2017) Factors Associated with Provider Burnout in the NICU. Pediatrics, 139, Article ID: e20164134. https://doi.org/10.1542/peds.2016-4134

[24] Skefales, A., Plakas, S., Fouka, G., Goni, M., Vassiliadou, M. and Bergiannaki, J.D. (2014) Burnout and Its Association with Working Conditions among Greek Hospital Nurses in a Time of Financial Crisis. Open Journal of Nursing, 4, 548-563. https://doi.org/10.4236/ojn.2014.47058

[25] Kagan, I. and Barnoy, S. (2013) Organizational Safety Culture and Medical Error Reporting by Israeli Nurses. Journal of Nursing Scholarship, 45, 273-280. https://doi.org/10.1111/jnu.12026

[26] Singer, S.J. and Vogus, T.J. (2013) Reducing Hospital Errors: Interventions That Build Safety Culture. Annual Review of Public Health, 34, 373-396.

https://doi.org/10.1146/annurev-publhealth-031912-114439

[27] Sexton, J.B., Adair, K.C., Leonard, M.W., Frankel, T.C., Proulx, J., Watson, S.R., et al. (2018) Providing Feedback Following Leadership WalkRounds Is Associated with Better Patient Safety Culture, Higher Employee Engagement and Lower Burnout. BMJ Quality \& Safety, 27, 261-270.

https://doi.org/10.1136/bmjqs-2016-006399

[28] Salyers, M.P., Bonfils, K.A., Luther, L., Firmin, R.L., White, D.A., Adams, E.L. and Rollins, A.L. (2017) The Relationship between Professional Burnout and Quality and Safety in Healthcare: A Meta-Analysis. Journal of General Internal Medicine, 32, 475-482. https://doi.org/10.1007/s11606-016-3886-9

[29] Lloyd, C. and Campion, D.P. (2017) Occupational Stress and the Importance of Self-Care and Resilience: Focus on Veterinary Nursing. Irish Veterinary Journal, 70, Article No. 30. https://doi.org/10.1186/s13620-017-0108-7

[30] Hart, P.L., Brannan, J.D. and De Chesnay, M. (2014) Resilience in Nurses: An Integrative Review. Journal of Nursing Management, 22, 720-734. https://doi.org/10.1111/j.1365-2834.2012.01485.x

[31] Ray-Sannerud, B.N., Leyshon, S. and Vallevik, V.B. (2015) Introducing Routine Measurement of Healthcare Worker's Well-Being as a Leading Indicator for Proactive Safety Management Systems Based on Resilience Engineering. Procedia Manu- 
facturing, 3, 319-326. https://doi.org/10.1016/j.promfg.2015.07.163

[32] Laal, F., Fazli, B., Balarak, D., Dalir, F., Mohammadi, M. and Mirzaei, R. (2016) Attitude toward the Patient Safety Culture in Healthcare Systems. Journal of Patient Safety \& Quality Improvement, 4, 363-368.

[33] Moss, M., Good, V.S., Gozal, D., Kleinpell, R. and Sessler, C.N. (2016) An Official Critical Care Societies Collaborative Statement: Burnout Syndrome in Critical Care Health Care Professionals: A Call for Action. American Journal of Critical Care, 25, 368-376. https://doi.org/10.4037/ajcc2016133

[34] Polit, D.F. and Beck, C.T. (2008) Nursing Research: Generating and Assessing Evidence for Nursing Practice. Lippincott Williams \& Wilkins, Philadelphia.

[35] Koivisto, K., Janhonen, S., Latvala, E. and Väisänen, L. (2001) Applying Ethical Guidelines in Nursing Research on People with Mental Illness. Nursing Ethics, 8, 328-339. https://doi.org/10.1177/096973300100800405

[36] Latvala, E., Janhonen, S. and Moring, J. (1998) Ethical Dilemmas in a Psychiatric Nursing Study. Nursing Ethics, 5, 27-35.

https://doi.org/10.1177/096973309800500104

[37] Hall, L.H., Johnson, J., Watt, I., Tsipa, A. and O’Connor, D.B. (2016) Healthcare Staff Wellbeing, Burnout, and Patient Safety: A Systematic Review. PLoS ONE, 11, Article ID: e0159015. https://doi.org/10.1371/journal.pone.0159015

[38] Cusack, K., Jonas, D.E., Forneris, C.A., Wines, C., Sonis, J., Middleton, J.C., et al. (2016) Psychological Treatments for Adults with Posttraumatic Stress Disorder: A Systematic Review and Meta-Analysis. Clinical Psychology Review, 43, 128-141. https://doi.org/10.1016/j.cpr.2015.10.003

[39] Dyrbye, L.N., West, C.P., Satele, D., Boone, S., Tan, L., Sloan, J. and Shanafelt, T.D. (2014) Burnout among US Medical Students, Residents, and Early Career Physicians Relative to the General US Population. Academic Medicine, 89, 443-451. https://doi.org/10.1097/ACM.0000000000000134

[40] Ghahramanian, A., Rezaei, T., Abdullahzadeh, F., Sheikhalipour, Z. and Dianat, I. (2017) Quality of Healthcare Services and Its Relationship with Patient Safety Culture and Nurse-Physician Professional Communication. Health Promotion Perspectives, 7, 168-174. https://doi.org/10.15171/hpp.2017.30

[41] Dyrbye, L.N., Shanafelt, T.D., Sinsky, C.A., Cipriano, P.F., Bhatt, J., Ommaya, A., et al. (2017) Burnout among Health Care Professionals: A Call to Explore and Address This Underrecognized Threat to Safe, High-Quality Care. NAM Perspectives. https://doi.org/10.31478/201707b 